\title{
Condylomata lata of the palms: an unusual site
}

\author{
M EL-SAAD EL-RIFAIE \\ From the Department of Dermatology, Kasr El-Eini Faculty of Medicine, Cairo University, Cairo, Egypt
}

SUMMARY In an unusual case of condylomata lata of the palms the development of moist hypertrophic papular eruptions is probably explained by the fact that the patient was a car-driver and had hyperhidrosis of the palms.

\section{Introduction}

Cutaneous lesions of secondary syphilis are very variable and simulate a wide variety of skin diseases. Condylomata lata, or syphilitic moist papules, appear usually in moist and warm areas of the body, particularly the anogenital region. In this report a case is described of condylomata lata on the palms of a car-driver with palmar hyperhidrosis.

\section{Case report}

A Yemenese heterosexual 25-year-old man was referred to the clinic of skin diseases in the King Faisal Hospital, Taif, Saudi Arabia, with a tongue lesion. The patient had consulted the doctor because of a low-grade fever, malaise, headache, and hoarseness of the voice of one week's duration; he was unaware of the palmar and tongue lesions.

On examination, the patient had generalised lymphadenopathy. The skin was clinically clear except for hyperhidrosis of the palms and numerous, dull greyish-white, moist papules $(6-10 \mathrm{~mm}$ in diameter), which occurred in particular on the creases of the right hand opposite the metacarpophalangeal joints (figure). The papules were flat, eroded, and oozing. The soles of the feet were not affected. Greyish-white mucus patches were seen on the tongue, although other mucus membranes appeared healthy.

Darkground examination of the moist papules and mucous patches showed Treponema pallidum. The Venereal Disease Research Laboratory (VDRL) and fluorescent treponemal antibody absorption (FTAABS) tests gave positive results. The patient stated that he had frequent sexual relations with prostitutes and had had an infected ulcer on the penis for two months before the present illness. He had treated the penile lesion himself with some local medication.

Address for reprints: Dr M El-Saad El-Rifaie, Department of Dermatology, Cairo University, 79 Kasr El-Eini Street, Cairo, Egypt

Received for publication 22 October 1979

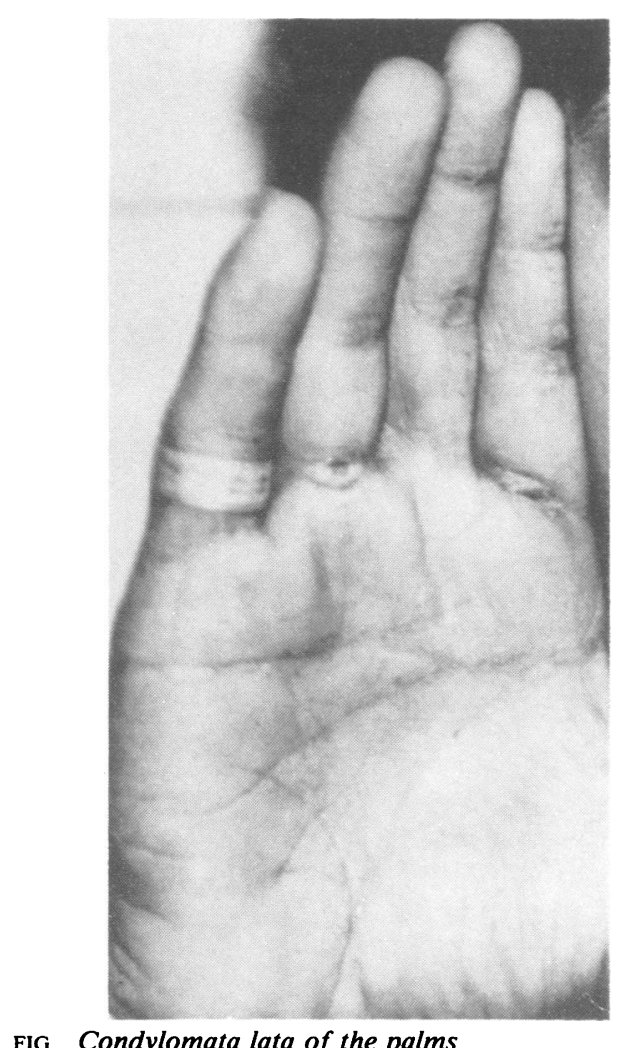

FIG Condylomata lata of the palms

The palmar lesions gradually resolved after treatment with two intramuscular injections of benzathine penicillin $2 \cdot 4$ megaunits at a week's interval.

\section{Discussion}

Condylomata lata are usually seen in moist and warm areas of the body, such as the anogenital region. Solitary lesions were reported in the toe-webs by Minkin et $a l,{ }^{1}$ and extensive condylomata lata were 
reported in an Indian patient by Shrivastava and Singh. ${ }^{2}$ In the present case, the site of the condylomata is unusual and, as far as I know, has not been reported before. Holding the steering wheel for long periods during driving together with hyperhidrosis of the palms probably explains the unusual site of this eruption. Cutaneous lesions of secondary syphilis may be inconspicuous, particularly when they are in unusual sites. In such cases a thorough clinical examination is important.
The author is indebted to Dr G El-Guindy for his cooperation.

\section{References}

1. Minkin W, Landy SE, Cohen HJ. An unusual solitary lesion of secondary syphilis. Arch Dermatol 1967;95:217.

2. Shrivastava SN, Singh G. Extensive condylomata lata. $\mathrm{Br} J$ Vener Dis 1977; 53:23-5. 